\title{
How Students' Mathematical Ideas Emerged through Flow of Lesson in Classroom Using Lesson Study and Open Approach
}

\author{
Pimpaka Intaros ${ }^{1,2}$, Maitree Inprasitha ${ }^{2,3}$ \\ ${ }^{1}$ Doctor Program in Mathematics Education, Faculty of Education, Khon Kaen University, Khonkaen, Thailand \\ ${ }^{2}$ Centre of Excellence in Mathematics, CHE, Si Ayutthaya RD., Bangkok, Thailand \\ ${ }^{3}$ Mathematics Education Program, Faculty of Education, Khon Kaen University, Khonkaen, Thailand \\ Email: ipimpaka@kkumail.com
}

How to cite this paper: Intaros, P., \& Inprasitha, M. (2019). How Students' Mathematical Ideas Emerged through Flow of Lesson in Classroom Using Lesson Study and Open Approach. Psychology, 10, 864-876.

https://doi.org/10.4236/psych.2019.106056

Received: April 23, 2019

Accepted: May 14, 2019

Published: May 17, 2019

Copyright () 2019 by author(s) and Scientific Research Publishing Inc. This work is licensed under the Creative Commons Attribution International License (CC BY 4.0).

http://creativecommons.org/licenses/by/4.0/

(c) (i) Open Access

\begin{abstract}
This study was aimed to analyze how students' mathematical ideas emerged through a flow of lesson in mathematics classroom using Lesson Study and Open Approach. A context of the study was the Open Approach as a teaching approach and the Lesson Study as a way to improve the quality of teaching (Inprasitha, 2015a). The flow of lesson, likewise, is considered to be a tool for accessing to students' ideas when the students are involved in problem solving and connection between students' real world and mathematical world (Inprasitha, 2017b). Ethnographic study was employed as a research methodology in this qualitative study by using a participative research design to form a lesson study team for collaborative designing of lesson plans guided by Thai version of Japanese mathematics textbooks. Research results were shown that the students' mathematical ideas emerged, through the flow of lesson, when the students' ideas of a problem solving were mathematized as follows: 1) the mathematical ideas were extended through representations of real world, 2) the mathematical ideas were extended and generalized through semi-concrete aids, and 3) the mathematical ideas were generalized through representations of mathematical world. The processes of mathematization (Isoda \& Katagiri, 2012), furthermore, were accomplished when the students' mathematical ideas become "how to" or tools for learning for the next lessons.
\end{abstract}

\section{Keywords}

Flow of Lesson, Students' Mathematical Ideas, Lesson Study, Open Approach, Mathematization, Extension, Generalization

\section{Introduction}

A concept of a new teaching practice relies on a new didactic triangle that 
changes a definition of learning entirely from a traditional didactic triangle in which components are teacher, student, and content. These components are reflected through a traditional teaching practice; the teacher passes on the contents to the students, and the students just memorize such knowledge. While the components of the new didactic triangle are teaching process, learning process, and thinking process. These components are related to the students' ideas used for accessing the students' learning or thinking processes (Inprasitha, 2017a, 2017b, 2018).

In Thai context, Inprasitha has proposed two innovations; Lesson Study and Open Approach, for changing a paradigm teaching practices of teachers and improving the teaching practices consecutively (Inprasitha et al., 2003, 2007). The Open Approach emphasizes on individual differences, especially differences in each students' thinking, composed of 4 phases: 1) Posing Open-ended Problem, 2) Students' Self-leaning, 3) Whole Class Discussion and Comparison, and 4) Summarize through Connecting Students' Mathematical Ideas Emerged in Classroom. The Lesson Study, besides, emphasizes on improving collaborative working of teachers for improving and developing the Open Approach directly, composed of 3 steps: 1) Collaboratively Design Research Lesson (Plan), 2) Collaboratively Observe Research Lesson (Do), and 3) Collaboratively Reflect on Teaching Practice (See) (Inprasitha, 2011, 2015a, 2015b). These two innovations are incorporated in the second step of the Lesson Study, as illustrated in Figure 1.

A classroom using the Lesson Study and Open Approach is a mathematics classroom where teachers use the Open Approach as a teaching approach and use the Lesson Study as a way to improve the teaching approach (Inprasitha, 2015a). Moreover, these could be done in a real classroom context, and challenging in working along the Lesson Study is identifying changes for students' learning improvement and interchange knowledge and problems with other teachers (Loipha \& Inprasitha, 2004; Inprasitha, 2014). The students, in addition,

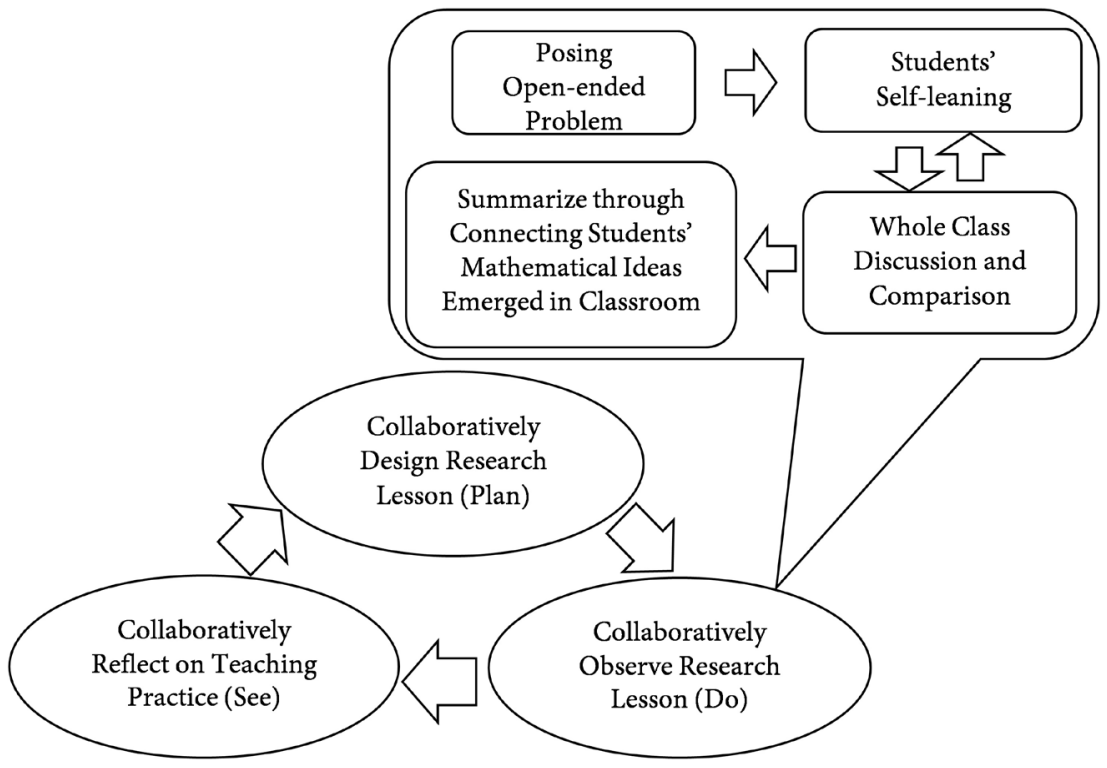

Figure 1. Open approach incorporated in lesson study (Inprasitha, 2010, 2011). 
could learn from sharing their ideas together. These ideas are derived from their own views along the problem situations and solving. In consequence of a principle of this classroom is accessing the students' ideas from the problem solving. Also, a lesson study team, which is composed of teachers who collaboratively plan, do, and see along the steps of the Lesson Study, would increasingly access and learn from the students' ideas in various ways (Inprasitha, 2011, 2015a). These are due to the subject matters of this classroom are students' ideas (Inprasitha, 2017b), which are different from a traditional classroom where the subject matters are other aspects.

Likewise, a new school mathematics has been increasingly called for in mathematics classroom, for instance, connection between out-of-school mathematics and school mathematics, adaptation of school mathematics in daily life of students, and also adaptation of out-of-school mathematics to make sense about school mathematics (de Abreu, 1995; National Council of Teachers of Mathematics [NCTM], 2000; Inprasitha, 2004, 2017b). This topic has been also mentioned in the 13th International Congress in Mathematical Education (ICME-13) (Gueudet, diSessa, \& Verschaffel, 2016). As a result, there are so extremely interests in mathematics educators. Connection of out-of-school mathematics and school mathematics, whereby, is due to enhancing the students' ideas in mathematical problem solving (Isoda, 2010).

Even though, there are constant requests about the connection of those mathematics, but there is nothing obviously in practices for a mathematics classroom. Therefore, a "Flow of Lesson" has been coined by Inprasitha (2017b), in order to connect students' real world and mathematical world, composed of three components; 1) Representations of real world 2) Semi-concrete aids 3) Representations of mathematical world. As a result, the students' ideas are accessible, and teachers use this tool for working together along the steps of the Lesson Study. Furthermore, in the mathematics classroom using the Lesson Study and the Open Approach, the flow of lesson has been applied for accessing the students' ideas. In addition, mathematization, in which is a process of making sense of mathematics when the students are involving problem solving, is finally employed to visualize the students' mathematical ideas. In other words, the students' ideas become students' mathematical ideas by extension and generalization. Furthermore, the mathematization composed of two components: 1) extension is a process of gradual changing from the students' ideas of problem solving to the ideas in which being more extensive, and 2) generalization is a process of gradual changing from the students' ideas of problem solving to the ideas in which being more complicated and could be adapted in common manners (Isoda \& Katagiri, 2012; Inprasitha \& Isoda, 2010, 2011).

As a result of how to access the students' mathematical ideas, this research would search for an enlightenment to teachers' comprehension of emerging of the students' mathematical ideas through the flow of lesson in the mathematics classroom using the Lesson Study and Open Approach. 


\section{Research Objective}

This study was aimed to analyze how students' mathematical ideas are emerged through a flow of lesson in the context of a mathematics classroom using the Lesson Study and Open Approach. These would support the teachers' comprehension about the emergence of the students' mathematical ideas by using the flow of lesson in which is the tool for the teachers to access the students' mathematical ideas.

\section{Research Methodology}

This research was a qualitative study and employed an ethnographic study as a research methodology in which the author-researcher participated as a member of a lesson study team. The lesson study team was composed of five members:

1) two in-service teachers who had been collaboratively working with pre-service to use the Lesson Study and Open Approach since 2009 academic year,

2) two pre-service teachers who were fifth-year students of the bachelor program in Mathematics Education, Faculty of Education, Khon Kaen University and had been collaboratively working with in-service teachers in the school for a year, and

3) the researcher, who had been a researcher assistant of the Center for Research in Mathematics Education, Khon Kaen University from 2009-2015 academic year.

This research was accomplished by a participatory research design in which the lesson study team collaboratively worked along the steps of the Lesson Study, details as follows:

1) collaboratively designed the lesson plans focusing on where the students' ideas could be emerged by using the flow of lesson,

2) collaboratively observed the teaching practices focusing on how the students' ideas become the students' mathematical ideas, and these teaching practices were taught by one member of the team,

3) collaboratively reflected about the teaching practices focusing on how the students' ideas were mathematized to be students' mathematical ideas through the flow of lesson.

\subsection{Unit of Analysis}

This study was decided to use the flow of lesson (Inprasitha, 2017b) in the Open Approach as a unit of analysis to analyze how the students' ideas were developed through the flow of lesson and were mathematized to be the students' mathematical ideas in the problem solving of the classroom using the Lesson Study and Open Approach, as following details.

Flow of Lesson (Inprasitha, 2017b) is a step of mathematics lesson in which started from the students' real world and connected to the students' mathematical world. It is composed of three components:

1) Representation of real world is a performance of using figure or other materials for communicating the students' real experience related to problem situations,

2) Semi-concrete aid is a performance of using relevant objects or concept re- 
lated to the students' ideas emerged from the students' understanding of problem situations and solving those problems,

3) Representation of mathematical world is a performance of using numbers and symbols for communicating mathematics meaningfully related to the students' ideas.

\subsection{Data Collection}

Data collection were done in grade 2 mathematics classroom in Thongchai Wittaya School, Lampang province, where located in the Northern of Thailand. This school has been participating in the Project of Students' Mathematical Higher Thinking Development in Northeastern of Thailand. In addition, this school has been using the Open Approach and the Lesson Study since 2009 academic year. Processes of data collection were started from 2016 academic year in which the researcher was in the school to collaboratively observed the students' mathematical learning in classroom with the in-service teachers and collaboratively reflected about the students' ideas emerged in the mathematics classroom. The data were done in 2017 academic year. In the 2017 academic year, there were all 8 second graders and these students were a targeted group.

The lesson study team collaboratively worked in a weekly cycle along steps of the Lesson Study, while the phases of the Open Approach are taken place in the second step (Inprasitha, 2010, 2011), and was guided by the project mathematics textbook-Thai version of Japanese mathematics textbooks, in the teaching practice of the Length (1) learning unit (Inprasitha \& Isoda, 2011).

The data were collected from the targeted group by these following research materials:

1) video-audio recording used while the ongoing processes of learning in classroom,

2) field note taken by the lesson study team except the teacher, and noted focusing on the students' ideas occurred from the problem solving and how they became the students' mathematical ideas, and

3) video-audio recording used while students were interviewed after finishing the problem solving in the classroom for inquiring more information about the students' ways of solving the problems.

These materials were proceeded under permission of those students who were the targeted group, in the processes of data collection that were done along 9 consecutive lesson plans. These lesson plans were conduced to establish a new how to or tool for learning of the next lessons.

These collected data were led to the data were used to analyze: 1) protocol of the students' problem solving and the students' interviews in which prescribed from video-audio tapes and 2) evidences of students' ideas in which prescribed from the field notes and students' written works. Lastly, they were triangulated to consider the students' mathematical ideas.

\subsection{Data Analysis}

Data analysis were relied on protocol analysis triangulated with field notes, stu- 
dents' written works, and protocol of the students' interviews, in according to two conceptual frameworks; Flow of Lesson (Inprasitha, 2017b) and Mathematization (Isoda \& Katagiri, 2012).

\section{Results}

Research results were shown from empirical evidences collected from the mathematics classroom using the Lesson Study and Open Approach that the students' mathematical ideas emerged when the students' ideas of a mathematical problem solving were mathematized by extension or generalization through the flow of lesson. As the first lesson, for example, the students' ideas were analyzed to find how the students' mathematical ideas emerged through the flow of lesson, as following details.

\subsection{Students' Mathematical Ideas Were Extended through Representations of Real World}

After the students found a problem in indicating of which clay-sculpted snake (they had sculpted) is longer, they firstly had an idea to use her hands and body as a measure tool of length by using her spreading hands and use her body by lay down along a length of the snakes, respectively. Then they were asked to compare the length of other clay-sculpted snakes by not moving. Then, they had realized that the measure tool should cover along the length after her hands and body could not cover all the length of the snakes. In this case, the hands and body were treated as the representation of real world, and the students used them for extension.

Therefore, the students had extended from the ideas of using the hands and body to puzzles and rulers in which can cover along the length, as the measure unit used for measuring the length, shown in empirical evidence as following protocol and illustrated in Figure 2, Figure 3, \& Figure 4, respectively.

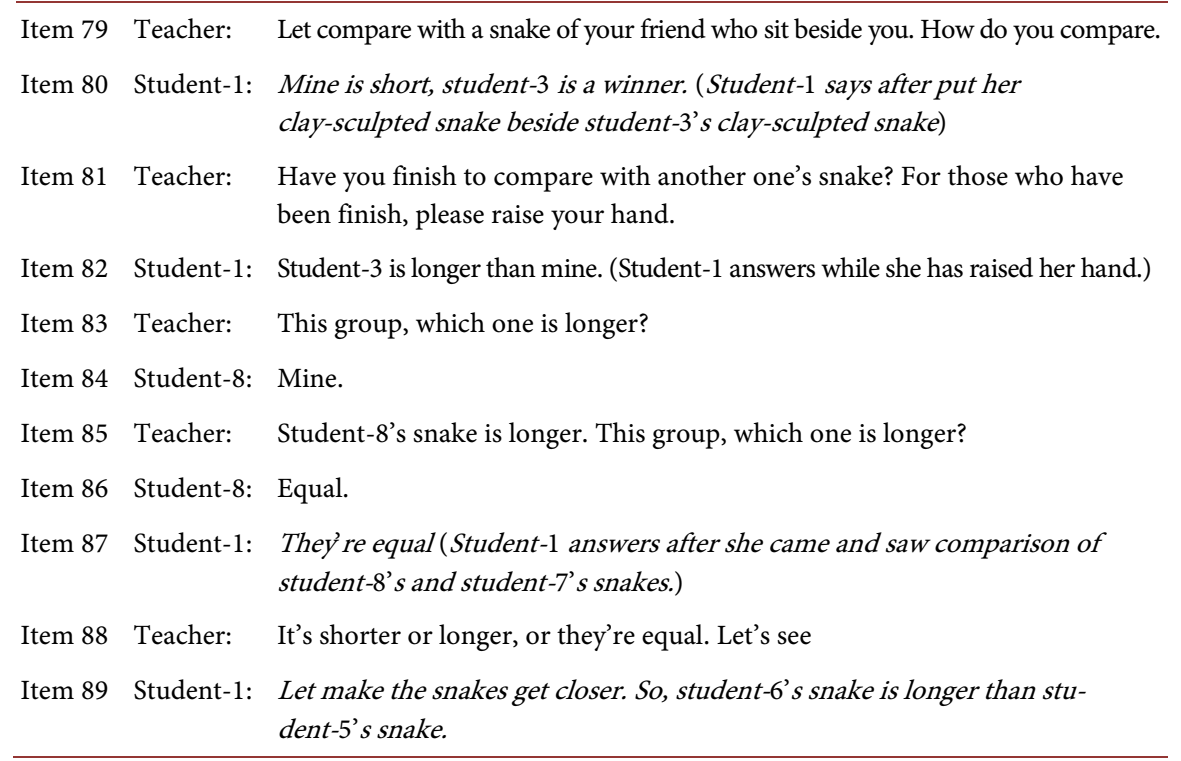




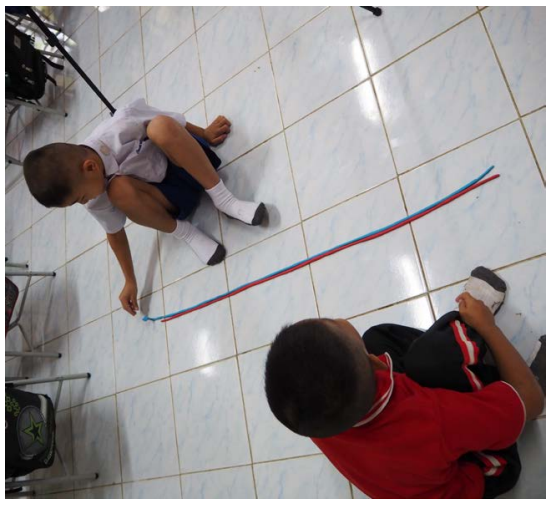

Figure 2. The students tried to compare clay-sculpted snakes directly.

Item 103 Teacher: Don't lift them up and drag them away. How could you compare with others?

Item 104 Student-1: Pll use my hand to be measure tool, then try to compare. My hands are about this.

Item 105 Teacher: What is your group's snake will be used to compare?

Item 106 Student-1: (Student-1 moves to compare with student-3's snake after the teacher already asked) Let me use my hands to support you to compare. Ah, I will lay down. Wow, I m equal to the snake. Teacher, it's equal to me when I was laid down.

Item 107 Student-2: Who do I have to compare with?

Item 108 Teacher: Group of student-1 compares with group of student-2, and group of student- 6 compares with group of student -8 .

Item 109 Student-1: Snake of student-3 is equal to me, from head to toe equally. I will lay my body down, let see if it's equal to student-2's snake.

Item 110 Teacher: Really? What did you choose to be a measure too?

Item 111 Student-1: Use my body as the measure tool.

Item 112 Teacher: Student-1 use your body as a measure tool. Let me see it again. (Student-1 lay down with a clay-sculpted snake of student- 2 again)

Everybody sees how the clay-sculpted snake be with the student-1, if it s equal to student-1, or how?

Item 113 Student-3: Student-1' feet, it's over her feet.

Item 114 Teacher: It's over her feet. How is about the clay-sculpted snake of student-3.

Item 115 Student-1: It's equal to me.

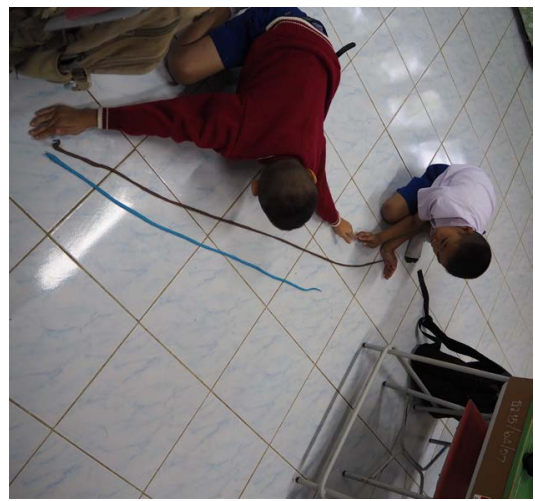

Figure 3. The student tried to use her hands to be a measure tool for measuring length. 


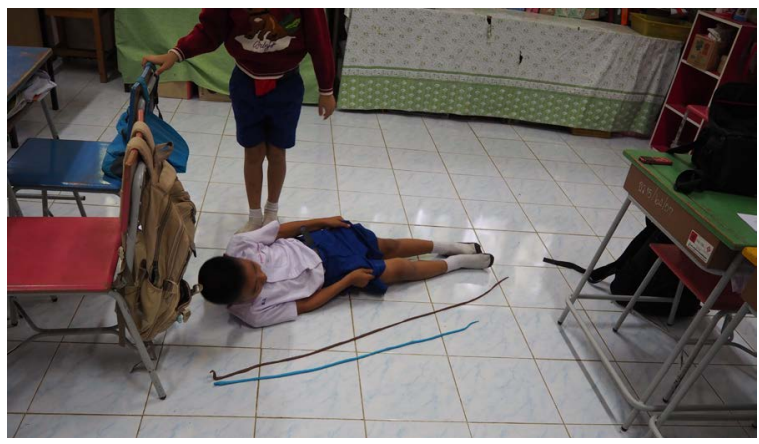

Figure 4. The student tried to use her body to be a measure tool for measuring length.

\subsection{Students' Mathematical Ideas Were Extended and Generalized through Semi-Concrete Aids}

\section{1) Students' mathematical ideas were extended through semi-concrete aids}

After the students found a problem of the measure tool should be easily used to measure stuffs, they had an idea to use puzzles put along a length of the snakes as a measure tool of length. In this case, the puzzles were treated as the semi-concrete aids, and the students used them for extension.

Therefore, they had extended the idea of from using the puzzles to the wood blocks in which are comfortable to measure and more stable than using the puzzles as the measure tool used for measuring the length.

2) Students' mathematical ideas were generalized through semi-concrete aids

After the students found a problem of identifying a measure unit from the measure tool they used, they had an idea to use a number of tiles to be a measure unit and then they could show the differences between those clay-sculpted snakes they tried to compare in more mathematically. In this case, the wood blocks used in the measurement were treated as the semi-concrete aids, and the students used them for generalization.

Therefore, the students had generalized the ideas of the number of the wood blocks they used firstly as measure tool, shown in empirical evidence as following protocol and illustrated in Figure 5 \& Figure 6.

\begin{tabular}{|c|c|c|}
\hline Item 202 & Teacher: & Are there anything else that isn't the rulers? \\
\hline Item 203 & Student-2: & $\begin{array}{l}\text { Puzzle! (Student-2 show the puzzles brought from stuffs placed besides the } \\
\text { classroom) }\end{array}$ \\
\hline Item 204 & Student-1: & This one! Everyone brings blocks to line up \\
\hline Item 205 & Teacher: & Blocks. I'll write it down. (Teacher write "blocks" on the board.) What else? \\
\hline Item 206 & Student-1: & $\begin{array}{l}\text { We can use these squares. (Student-1 point out to the squares used to be a } \\
\text { floor of the classroom) }\end{array}$ \\
\hline Item 207 & Teacher: & What's we call the square? \\
\hline Item 208 & Student-8 & Tiles. \\
\hline Item 209 & Teacher: & Square of tiles, right? Are they equa? \\
\hline Item 210 & Student-1: & $\begin{array}{l}\text { Try to put the snakes here. } \\
\text { One, two, three, four. Four and a bit more is a length of this snake. }\end{array}$ \\
\hline Item 211 & Teacher: & Square of tiles. (Teacher write 'square of tiles' on the board.) \\
\hline
\end{tabular}




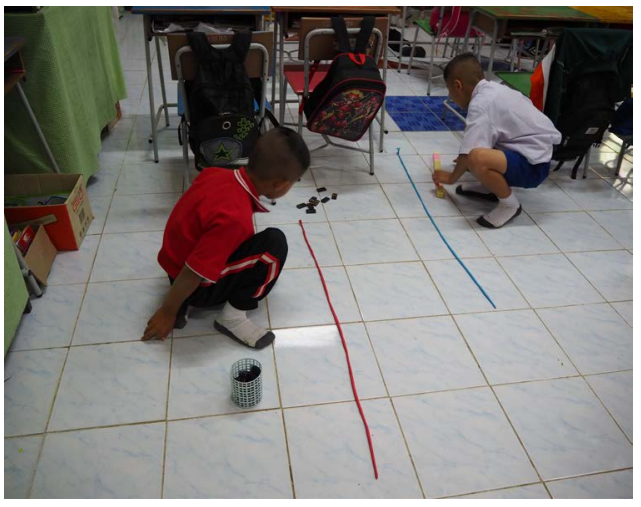

Figure 5. The students tried to use the puzzles to be a measure tool for measuring length.

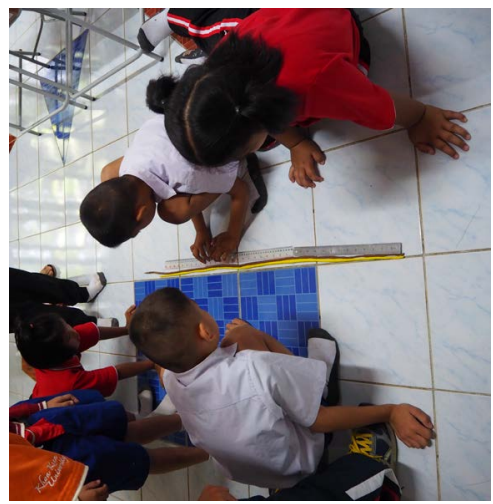

Figure 6. The students tried to use the rulers to be a measure tool for measuring length.

\subsection{Students' Mathematical Ideas Were Generalized through Representations of Mathematical World}

After the students found a problem in identifying a measure unit, they had an idea to use the number of wood blocks as a measure unit. In this case, the number of wood blocks were treated as the representation of mathematical world, and the students used them for generalization.

Therefore, the students had generalized the ideas of the number of the wood blocks they used as the arbitrary measure unit used for measuring the length, shown in empirical evidence as following protocol and illustrated in Figure 7.

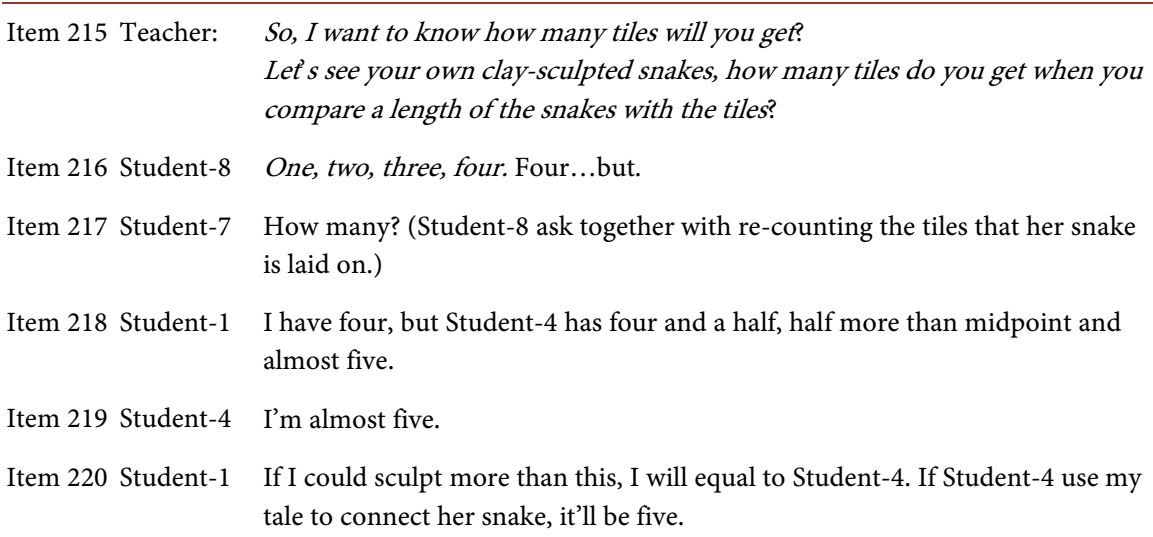




\section{Continued}
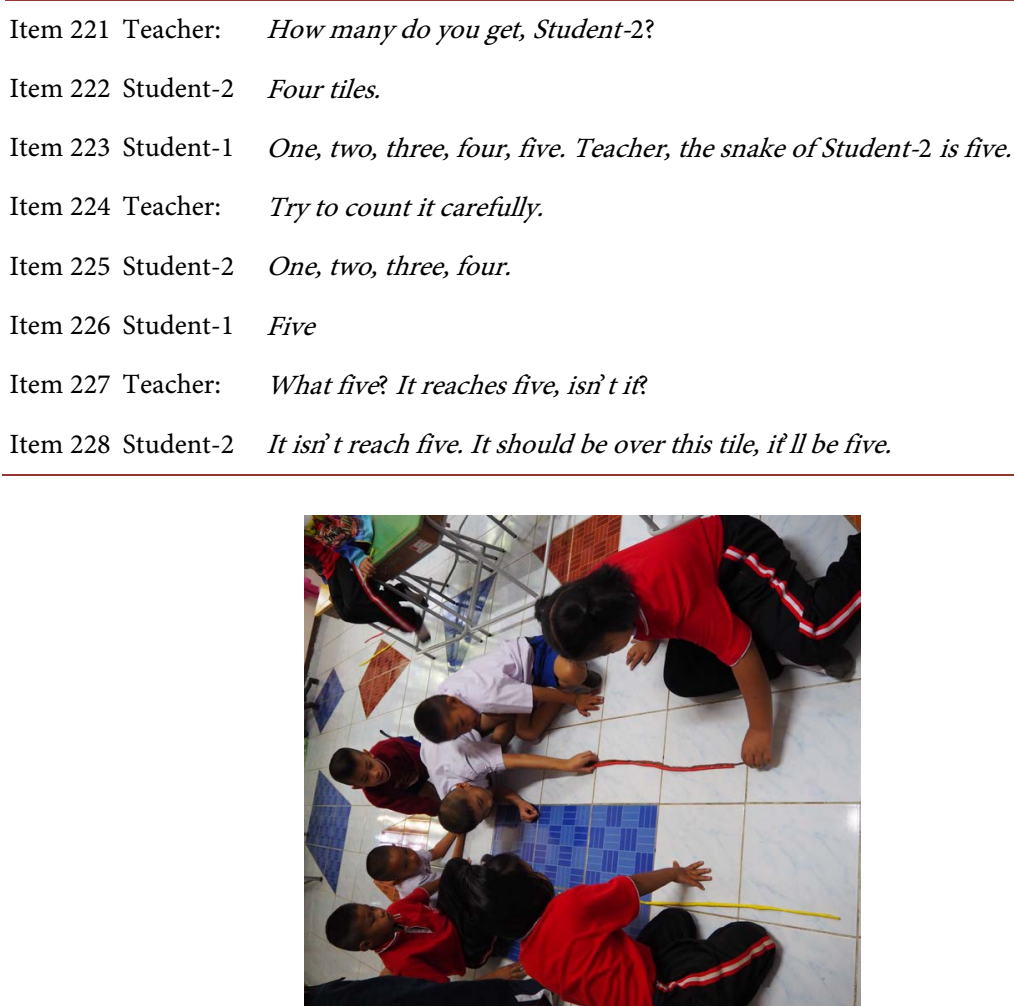

Figure 7. The students tried to use the square of tiles to be a measure tool for measuring length.

The processes of extension and generalization were done when the ideas of the students gradually become "how to" or tool for learning (Inprasitha \& Isoda, 2010, 2011) of the students used to learn next mathematics lessons continuously. This lesson the arbitrary measure unit as the students' mathematical ideas has become the "how to" when the students could use any stuffs to be the arbitrary measure unit of length with the same shape of such stuff.

Overall, the Length (1) learning unit in which composed of 9 lesson plans, the students in classroom using the Lesson Study and Open Approach could produce the mathematical ideas through the flow of lesson as following Table 1.

Table 1. Students' mathematical ideas emerged through flow of lesson in mathematization in classroom using lesson study and open approach.

\begin{tabular}{|c|c|c|c|c|c|c|c|c|c|}
\hline \multirow{2}{*}{ Students' Mathematical Ideas were Mathematized through Flow of Lesson } & \multicolumn{9}{|c|}{ Lessons } \\
\hline & 1 & 2 & 3 & 4 & 5 & 6 & 7 & 8 & 9 \\
\hline Students' mathematical ideas were extended through representations of real world & $\checkmark$ & $\checkmark$ & $\checkmark$ & $\checkmark$ & $\checkmark$ & $\checkmark$ & $\checkmark$ & $\checkmark$ & $\checkmark$ \\
\hline Students' mathematical ideas were generalized through Representations of real world & - & - & - & - & - & - & - & - & - \\
\hline Students' mathematical ideas were extended through semi-concrete aids & $\checkmark$ & $\checkmark$ & $\checkmark$ & $\checkmark$ & $\checkmark$ & $\checkmark$ & $\checkmark$ & $\checkmark$ & $\checkmark$ \\
\hline Students' mathematical ideas were generalized through Semi-concrete aids & $\checkmark$ & $\checkmark$ & $\checkmark$ & $\checkmark$ & $\checkmark$ & $\checkmark$ & $\checkmark$ & $\checkmark$ & $\checkmark$ \\
\hline Students' mathematical ideas were extended through representations of mathematical world & - & - & - & - & - & - & - & - & - \\
\hline Students' mathematical ideas were generalized through representations of mathematical world & $\checkmark$ & $\checkmark$ & $\checkmark$ & $\checkmark$ & $\checkmark$ & $\checkmark$ & $\checkmark$ & $\checkmark$ & $\checkmark$ \\
\hline
\end{tabular}


From the above mentions, there were not students' mathematical ideas were generalized through representation of real world and were extended through representation of mathematical world appeared in the mathematical classroom when the students were involved in problem solving. These were due to the representation of real world will be almost used to connect to the students' experiences. It could be, as a result, hastily to be generalized to be students' mathematical ideas. Similarly, the representation of mathematical world in which closed to the students' mathematical world. Therefore, it is quite complicated for the students to use the representation of mathematical world for extension. In other words, the components of the flow of lesson is a sequencing, starting from the representation of real world, developing through the semi-concrete aids, and connecting to the representation of mathematical world, respectively.

\section{Discussions and Concluding Remarks}

The results reflected from the evidences in mathematics classroom using the Lesson Study and Open Approach have shown that the flow of lesson could be as an assistance of the teachers who collaboratively plan, do (teach or observe), and see (reflect) together to comprehend the students' ideas which were mathematized in the students' mathematical problem solving to reach how the students' ideas gradually develop and then become the students' mathematical ideas.

In addition, Nunes, Schliemann \& Carraher (1993), de Abreu (1995), Swanson \& Williams (2014), and more, studied about a relationship of a school mathematics and an outside school mathematics. These studies have the obvious results according to the activities used in the classroom which should be related to students' experiences. This could help the students adapt their experiences to make sense of such activities. As a result, the students could develop the mathematical ideas from their own experiences in daily life.

In conclusion, using extension and generalization (Isoda \& Katagiri, 2012) to grasp the students' mathematical ideas emerged through the flow of lesson (Inprasitha, 2017b) is advantaged to comprehend a goal of the lesson based on the students' ideas. The teachers, subsequently, should utilize the flow of lesson to access the students' ideas in planning the lessons, then teaching in according to the students' ideas, and at the same time, observing the students' ideas which emerged in the classroom. Finally, the teachers should use the mathematization as a lens to comprehend the students' mathematical ideas for supporting the ideas to reach the goal of the lesson eventually. These conclusions are coherent to Harel (2004) who stated that students do not learn mathematics by merely presenting them with clear concept definitions in forms of axioms, definitions theorems and formal proofs, although formal concepts definitions may be an ultimate goal of mathematics learning. Furthermore, these conclusions are similar to Lakoff \& Nunez (2000) who stated that these limitations play a crucial role in the students' mathematization processes.

Finally, these conclusions enlighten the teachers to comprehend how the flow 
of lesson assists the teachers to recognize the students' mathematical ideas distinctly. Also, the processes of extension and generalization were accomplished when the students' mathematical ideas become "how to" or tool for learning of the next lessons. These are in accordant to Suriyon, Inprasitha \& Sangaroon (2013) which stated that the teaching practice allowing students to create knowledge from learning how to solve problems by themselves led to forming "students' metacognitive strategies" or "how to" learn mathematics by themselves.

\section{Acknowledgements}

This study is granted by the Centre of Excellence in Mathematics, the Commission on Higher Education, Thailand, and supported by the Project of Students' Mathematical Higher Thinking Development in Northeastern of Thailand, and the Center for Research in Mathematics Education, Khon Kaen University.

\section{Conflicts of Interest}

The authors declare no conflicts of interest regarding the publication of this paper.

\section{References}

de Abreu, G. (1995). Understanding How Children Experience the Relationship between Home and School Mathematics. Mind, Culture, and Activity, 2, 119-142. https://doi.org/10.1080/10749039509524693

Gueudet, G., BoschAndrea, M., diSessa, A., Kwon, O. N., \& Verschaffel, L. (2016). Transitions in Mathematics Education. Plenary Activities in the ICME-13 (13th International Congress in Mathematical Education), 24-31 July 2016, Hamburg, Germany. https://doi.org/10.1007/978-3-319-31622-2

Harel, G. (2004). Perspective on Concept Image and Concept Definition in Mathematics with Particular Reference to Limit and Continuity. In T. P. Carpenter, J. A. Dossey, \& J. L. Koehler (Eds.), Classics in Mathematics Education Research. Reston, VA: NTCM.

Inprasitha, M. (2004). Curriculum of Bachelor in Mathematics Education, Faculty of Education, Khon Kaen University. Khonkaen: Khonkaen University.

Inprasitha, M. (2010). One Feature of Adaptive Lesson Study in Thailand: Designing Learning Unit. In Proceedings of 45th Korean National Meeting of Mathematics Education (pp. 193-206). Korea: Dongkook University.

Inprasitha, M. (2011). One Feature of Adaptive Lesson Study in Thailand: Designing a Learning Unit. Journal of Science and Mathematics Education in Southeast Asia, 34, 47-66.

Inprasitha, M. (2014). Processes of Problem Solving in School Mathematics. Khonkaen: Pen Printing. (In Thai)

Inprasitha, M. (2015a). New Model of Teacher Education Program in Mathematics Education: Thailand Experience. In Proceedings of 7th ICMI-East Asia Regional Conference on Mathematics Education (pp. 97-103). Cebu City, Philippines: EARCOME.

Inprasitha, M. (2015b). Transforming Education through Lesson Study: Thailand's Decade-Long Journey. In M. Inprasitha, M. Isoda, P. Wang-Iverson, \& B. H. Yeap (Eds.), Lesson Study: Challenges in Mathematics Education (pp. 213-228). Singapore: World Scientific. https://doi.org/10.1142/9789812835420_0014 
Inprasitha, M. (2017a). Lesson Study and Open Approach Innovations for Enhancing Classroom Quality and Kyozaikenkyu in Lesson Study and Open Approach. In Paper presented at Workshop for School Teachers in the Project of Students' Mathematical Higher Thinking Development in Northeastern of Thailand. Khonkaen: Khon Kaen University. (In Thai)

Inprasitha, M. (2017b). Understanding School Mathematics through Analysis of Mathematics Textbook. In Paper Presented at the 27th Intensive Seminar. Khonkaen: Khon Kaen University. (In Thai)

Inprasitha, M. (2018). Open Approach Lesson Study: An Authentic PLC Practice in School. In Paper Presented at the 12th National Open Class. Khonkaen: Khon Kaen University. (In Thai)

Inprasitha, M. et al. (2003). School Mathematics Learning Reform Emphasized on Mathematical Processes. Khonkaen: Khonkaen Karnpim. (In Thai)

Inprasitha, M. et al. (2007). Context Preparation for Adaptation of Teachers Professional Development "Lesson Study" in Thailand. In S. Wajjwalku, \& K. Prasirtsuk (Eds.), Proceedings of the 1st National Conference Japan Studies Network in Thailand (Sociology) (pp. 152-163). Bangkok: Sangsue. (In Thai)

Inprasitha, M. \& Isoda, M. (Eds.) (2010). Mathematics for Elementary School: Grade 1. Khonkaen: Klangnana Wittaya. (In Thai)

Inprasitha, M., \& Isoda, M. (Eds.) (2011). Mathematics for Elementary School: Grade 2-6. Khonkaen: Klangnana Wittaya. (In Thai)

Isoda, M. (2010). Lesson Study: Problem Solving Approaches in Mathematics Education as a Japanese Experience. Procedia-Social and Behavioral Sciences, 8, 17-27. https://doi.org/10.1016/j.sbspro.2010.12.003

Isoda, M., \& Katagiri, S. (Eds.) (2012). Mathematical Thinking: How to Develop It in the Classroom. Singapore: World Scientific. https://doi.org/10.1142/8163

Lakoff, G., \& Nunez, R. E. (2000). Where Mathematics Comes from: How the Embodied Mind Brings Mathematics into Being. New York: Basic Books.

Loipha, S., \& Inprasitha, M. (2004). Teachers Professional Development for Supporting Mathematics Learning. KKU Journal of Mathematics Education, 1, 18-28. (In Thai)

National Council of Teachers of Mathematics (NCTM) (2000). Principles and Standards for School Mathematics. Reston: The National Council of Teachers of Mathematics.

Nunes, T., Schliemann, A. D., \& Carraher, D. W. (1993). Street Mathematics and School Mathematics. Cambridge: Cambridge University Press.

Suriyon, A., Inprasitha, M., \& Sangaroon, K. (2013). Contextual Factors in the Open Approach-Based Mathematics Classroom Affecting Development of Students' Metacognitive Strategies. Sociology Mind, 3, 284-289. https://doi.org/10.4236/sm.2013.34038

Swanson, D., \& Williams, J. (2014). Making Abstract Mathematics Concrete in and out of School. Educational Studies in Mathematics, 86, 193-209.

https://doi.org/10.1007/s10649-014-9536-4 